(17\%) and driving seat vibration (10.1\%). The options available in vehicles for drivers comfort looked insufficient in most of the heavy vehicles (availability of Air Conditioning (4.8\%), Automatic gear transmission $(0.8 \%)$ and availability of head rest in driving seat $(43.4 \%)$ were not adequate. The emerging hazard of "inattention blindness" in driving due to use of cell phones while driving (18.2\%) was also noted among Sri Lankan heavy vehicle drivers in significant level.

Conclusions The study shows that road safety research needs to go beyond common RTI risk factors and analyse risks involved with the health status of drivers. And it suggests that strengthening of quality control of heavy vehicles, health education and regular monitoring of health status of heavy vehicle drivers is vital to improve the status of countries injury prevention efforts.

\section{INVESTIGATING CHARACTERISTICS OF WORK ZONE AND NON-WORK ZONE CRASHES ON NATIONAL HIGHWAY-8, INDIA}

Sumeet Gupta, Abhaya Jha, Geetam Tiwari. Indian Institute of Technology Delhi, New Delhi, India

\subsection{6/injuryprev-2016-042156.143}

Background The continuously increasing number of road construction and maintenance projects in India, especially on highways, creates huge risk for road users. This prompted us to examine the difference between characteristics of fatal crashes in Work Zones (WZs) and Non-Work Zones (NWZs).

Methods The study included analysis of fatal crash data for the period November 2009 to December 2013. Crash parameters such as the date, time, collision type, type of victim, i.e., pedestrian/cyclist/car user, etc., victim's age, vehicle type, number of persons injured/killed etc., were extracted from fatal crash records. WZ crashes were extracted from the main crash database. The design chainage, length, start date and end date of each WZ was obtained from the concessionaire.

Results The crash rate is higher in WZs (1.68 crashes $/ \mathrm{km} / \mathrm{year})$ as compared to Non-WZs (1.32 crashes $/ \mathrm{km} / \mathrm{year}) .77 \%$ and $71 \%$ of WZ and NWZ fatalities respectively involved vulnerable road users (pedestrians, bicyclists and motorised two wheeler riders) as victims. A higher proportion of working age group people (2660 years) are involved in both WZs (46\%) and NWZs (48\%). Fatal crashes in both WZs and NWZs are more likely to be involved with another vehicle (nearly 95\%). "Hit pedestrian" crashes were the dominant type in both WZs (41\%) and NWZs (39\%). Trucks are involved (as a striking vehicle) in a higher proportion of fatalities in both WZ (52\%) and NWZ (54\%) locations.

Conclusions The proportion of fatalities and fatal crashes are very similar in both WZs and NWZs but the rate of fatal crashes is comparatively higher in WZs. The predominance of hit pedestrian crashes, especially, in WZs, strongly indicates that one of the causal factors is over speeding. The implementation of a countermeasure like rumble strips that forces drivers to drive at approximately the same speeds throughout the WZs will improve safety at WZs significantly.

\section{ROAD TRAFFIC INJURY MORTALITY, MORBIDITY AND DISABILITY: EVIDENCE FROM BANGLADESH HEALTH AND INJURY SURVEY (BHIS)}

${ }^{1}$ Baset Md Kamran ul, ${ }^{1}$ Rahman Aminur, ${ }^{1}$ Mashreky Saidur Rahman, 'Talab Abu, 'Rahman AKM Fazlur, ${ }^{2}$ Towner Elizabeth. ${ }^{1}$ Centre for Injury Prevention and Research, Bangladesh (CIPRB): ${ }^{2}$ University of the West of England

\subsection{6/injuryprev-2016-042156.144}

Introduction Road traffic injuries (RTIs) are a leading cause of morbidity, disability and mortality in low income countries. In 2004 nearly 1.3 million people of all ages were killed in road traffic crashes and over 50 million were injured or disabled. There are indications that road traffic injury fatalities and morbidities are increasing in Bangladesh.

Objective Investigate the magnitude of and risk factors for road traffic injury in Bangladesh.

Methodology A cross sectional study was conducted to explore the magnitude of mortalities and disabilities due to RTIs. Face-toface interviews were used. Multi stage cluster sampling was used to select the sample.

Results Data were collected from 171,366 rural and urban households, covering a population of 819,429 . The overall incidence of RTIs fatality was 12.9 per 100,000 population. The mortality rate gradually rose from children under 5 and peaked in the older age group, 55 years and above, $(21.4$ per 100,000$)$. The overall rate of non-fatal RTI was calculated as 134.5 per 100,000 . The highest incidence (165.7 per 100,000$)$ was in the $20-39$ years age group. A significantly higher rate of RTI mortality and morbidity was observed among males. The incidence of RTI was found to be three times higher in rural than urban areas. Most RTIs were non motorised vehicle and pedestrian injuries. The highest rate of RTI disability was found among males, aged 30-54 years.

Conclusion Road traffic injury is an important public health issue in Bangladesh. Immediate attention should be made to strengthen preventive intervention measures.

\section{Occupational safety}

\section{Parallel Mon 2.4}

\section{AGRICULTURAL SAFETY \& HEALTH MANAGEMENT PLANNING}

Dennis J Murphy. Penn State University, USA

\subsection{6/injuryprev-2016-042156.145}

Background Agricultural producers lack an easily understandable reference to help them develop a comprehensive safety and health plan for their operation. While many examples of safety management plans exist for general industry, they do not relate well to the hazards and risk of agriculture.

Objective To develop an agricultural safety and health management plan reference manual applicable to a wide range of agricultural operations.

Results The manual Safety and Health Management Planning for General Farm and Ranch Operations. The major sections of this 